Revista Brasileira de Agricultura Irrigada v.11, nº.6, p. 1813 - 1824, 2017

ISSN 1982-7679 (On-line)

Fortaleza, CE, INOVAGRI - http://www.inovagri.org.br

DOI: $10.7127 /$ rbai.v11n600629

Protocolo 629.17 - 16/03/2017 Aprovado em 17/07/2017

\title{
ESTRESSE SALINO EM PLANTAS DE PIMENTÃO EM SISTEMA SEMI- HIDROPÔNICO SOB FERTILIZAÇÃO ORGÂNICA E MINERAL
}

Keivianne da Silva Lima Reges ${ }^{1}$, Thales Vinicus de Araújo Viana ${ }^{2}$, Geocleber Gomes de Sousa $^{3}$, Francisco Sildemberny Souza Santos ${ }^{4}$, Claudivan Feitosa de Lacerda ${ }^{5}$, Benito Moreira de Azevedo ${ }^{2}$

\section{RESUMO}

Objetivou-se avaliar os efeitos do estresse salino em sistema semi-hidropônico na biomassa e nos teores de N, P, K, Ca e Mg em plantas de pimentão sob fertilização orgânica e mineral. A pesquisa foi conduzida em sistema semi-hidroponico em Limoeiro do Norte, CE. O delineamento experimental foi o de blocos casualizados em esquema fatorial $5 \mathrm{x} 4$, referentes as diferentes concentrações de água salina $\left(0,5 ; 1,5 ; 3,0 ; 5,0\right.$; e $\left.7,5 \mathrm{dS} \mathrm{m}^{-1}\right)$ e 4 doses de aplicações de fertilizantes na solução nutritiva $(\mathrm{D} 1=50 \%$ da dose recomendada; $\mathrm{D} 2=100 \%$ da dose recomendada e D3 $=150 \%$ da dose recomendada na forma orgânica e D4 $=100 \%$ da dose recomendada na forma mineral, com 4 repetições. A irrigação com água salina até 3,0 dS $\mathrm{m}^{-1}$ promove maior massa seca da parte aérea, raiz e total da cultura do pimentão quando adubada com $100 \%$ da dose recomendada de biofertilizante. A salinidade da água de irrigação afeta o teor de $\mathrm{N}$ com $100 \%$ da dose recomendada de biofertilizante e na adubação mineral, o teor de P com 50, 100 e 150\% da dose recomendada de biofertilizante e a partir da CEa 3,76 com adubação mineral e o teor de $\mathrm{Ca}$ e $\mathrm{K}$ em todas as adubações. O cultivo do pimentão adubado com fonte orgânica ou mineral em sistema semi-hidropônico é uma alternativa viável para a utilização da água de rejeito da dessalinização evitando a contaminação do lençol freático.

Palavras-chave: Capsicum annuum L., salinidade, nutrição de plantas

\section{SALT STRESS IN PEPPER PLANTS IN SEMI-HYDROPONIC SYSTEM UNDER ORGANIC FERTILIZATION AND MINERAL}

\author{
ABSTRACT \\ ${ }^{1}$ Mestre em Ciência do Solo, UFC, e-mail: kei-via@hotmail.com \\ 2 Doutor em Engenharia Agrícola, Prof. da UFC, e-mail:thales@ufc.br; benitoazevedo@hotmail.com \\ ${ }^{3}$ Doutor em Engenharia Agrícola, Prof. da UNILAB, e-mail:sousagg@unilab.edu.br \\ ${ }^{4}$ Doutor em Engenharia Agrícola, Prof. da IFCE, Campus de Limoeiro do Norte, e-mail: \\ sildemberny@hotmail.com \\ ${ }^{5}$ Doutor em Fisiologia Vegetal, Prof. da UFC, e-mail: cfeitosa@ufc.br
}


This study was aimed at evaluating the effects evaluate the effects of using the salt stress and system semi-hydroponics in the biomass and leaf $\mathrm{N}, \mathrm{P}, \mathrm{K}, \mathrm{Ca}$ and $\mathrm{Mg}$ contents on the chili plant.The research was conducted in open type semi-hydroponic system in Limoeiro do Norte, CE. The experimental design was a randomized complete block design in a $5 \times 4$ factorial scheme, with reference to the different concentrations of saline water $(0.5,1.5,3.0,5.0$ and 7.5 $\mathrm{dS} \mathrm{m}-1$ ) and $4 \mathrm{D} 2=100 \%$ of the recommended dose and D3 $=150 \%$ of the recommended dose in organic form and D4 $=100 \%$ of the recommended dose in the mineral form, with 4 replicates. Fertilization $100 \%$ of the recommended dose of biofertilizers promotes greater shoot dry mass, root and total culture Chili when used with moderate levels of salinity $\left(3.0 \mathrm{dS} \mathrm{m}^{-1}\right)$ in the irrigation water. The salinity irrigation water affects the N content to $100 \%$ of the recommended dose of biofertilizer and mineral fertilizer, the content of $\mathrm{P} 50,100$ and $150 \%$ of the recommended dose of biofertilizers and from EC 3.76 with mineral fertilizer Ca and K content in all fertilization. The cultivation of the sweet pepper fertilized with organic or mineral source in a semi-hydroponic system is a viable alternative for the use of waste water from desalination, avoiding the contamination of the water table.

Keywords: Capsicum annuum L, salinity, plant nutrition

\section{INTRODUÇÃO}

A cultura do pimentão (Capsicum annuum L.), pertencente à família das solanáceas e apresenta elevado valor comercial, sendo classificada entre as dez hortaliças mais consumidas no Brasil, ocupando 8.291 hectares, com produção de 70 mil toneladas e gera 4543 empregos, sendo o $6^{\circ}$ produto agrícola em demanda de força de trabalho (HORTIBRASIL, 2016). Segundo dados da FAO (2013), a China é maior produtor mundial de pimentão, com 22 t ha ${ }^{-1}$. Quanto a condutividade elétrica da água, o pimentão tolera a até $2,2 \mathrm{dS} \mathrm{m}^{-1}$, sem redução na produtividade (AYERS; WESTCOT, 1999)

A escassez de recursos hídricos na região nordeste tem evidenciado o uso de água salina na agricultura como uma alternativa importante para a produtividade agrícola. No entanto, quando não se faz um manejo adequado com relação ao uso dessa água, pode inibir o crescimento das plantas em razão da redução do potencial osmótico da solução do solo, restringindo a disponibilidade de água e/ou pela acumulação excessiva de íons nos tecidos vegetais, podendo ocasionar toxicidade iônica, desequilíbrio nutricional, ou ambos (SOUSA et al., 2010).

No cultivo semi-hidropônico a tolerância das plantas à salinidade é maior em relação ao sistema convencional, devido a nulidade do potencial mátrico, o que reduz ao máximo os efeitos danosos da salinidade nos diferentes estádios de crescimento (SANTOS JÚNIOR et al., 2015). Outro beneficio gerado por esse sistema de cultivo é que a salinidade proporciona menor consumo hídrico das plantas (SILVA et al., 2012). Ressalta-se que o estresse salino provoca efeito osmótico e específico de íons, que entram no fluxo de transpiração e, eventualmente, causam injúrias nas folhas, reduzindo o crescimento ou influenciando negativamente na absorção de elementos essenciais (MUNNS, 2005).

Além do sistema semi-hidropônico uma alternativa utilizada para minimizar os efeitos deletérios da salinidade sobre o solo e as plantas, é o uso de biofertilizante bovino que tem evidenciado atenuar os efeitos do estresse salino no crescimento inicial e na composição mineral de algumas culturas (CAVALCANTE et al., 2011; SILVA et al., 2011).

O biofertilizante vem sendo considerado como uma estratégia para atenuar o estresse salino, ativando o crescimento das plantas, como reportam Sousa et al. (2014) na cultura do feijão, melhorando as trocas gasosas (GOMES et al., 2015) e melhorando na absorção de nutrientes (SILVA et al., 2011).

Diante o exposto objetivou-se avaliar os efeitos do uso de água salina em sistema semihidropônico no acúmulo de biomassa e nos teores de $\mathrm{N}, \mathrm{P}, \mathrm{K}$, Ca e $\mathrm{Mg}$ em plantas de pimentão sob fertilização orgânica e mineral. 


\section{MATERIAL E MÉTODOS}

O trabalho foi realizado na Unidade de Ensino, Pesquisa e Extensão (UEPE), Chapada do Apodi, numa área pertencente ao Instituto Federal de Educação, Ciência e Tecnologia do Ceará - IFCE, localizada no município de Limoeiro do Norte, CE.

O local tem altitude de 151 metros e está situado à $05^{\circ} 06^{\prime}$ 'S e $37^{\circ} 52^{\prime} \mathrm{W}$. Apresenta como valores médios anuais, temperatura de $28,5^{\circ} \mathrm{C}$, umidade relativa do ar de $62 \%$, precipitações anuais de $772 \mathrm{~mm}$, concentrando-se entre março e maio, sendo que de julho a dezembro ocorre o período mais seco. De acordo com a classificação de Köppen, o clima local é do tipo BSw’h', tido como semiárido, com máximo de chuvas no outono e muito quente (DNOCS, 2011).

Os tratamentos com salinidade (Tabela 2) foram definidos após os resultados das análises físico-químicas das águas residuárias coletadas no sítio Catumbela, pertencente ao município de Russas-CE (CA) e Bela vista, pertencente ao município de Limoeiro do Norte, CE (BV) (Tabela 1).

Tabela 1. Análise química das águas dos rejeitos de dessalinizador, pertencente ao município de RussasCE (CA) e Bela vista, pertencente ao município de Limoeiro do Norte, CE (BV).

\begin{tabular}{cccccccccccc}
\hline \multirow{2}{*}{ LOCAL } & $\mathrm{Ca}^{2+}$ & $\mathrm{Mg}^{2+}$ & $\mathrm{Na}^{+}$ & $\mathrm{K}^{+}$ & $\mathrm{Cl}^{-}$ & $\mathrm{SO}_{4}{ }^{2-}$ & $\mathrm{HCO}_{3}^{-}$ & $\mathrm{CO}_{3}{ }^{2-}$ & $\mathrm{CE}$ & $\mathrm{RAS}$ & $\mathrm{pH}$ \\
\cline { 2 - 27 } \\
CA & 23,6 & 9,73 & 6,86 & 1,71 & 24,31 & 1,02 & 4,9 & - & 9,97 & 1,68 & 7,5 \\
\hline BV & 4,94 & 5,87 & 11,89 & 1,18 & 18,65 & 0,08 & 1,39 & - & 3,13 & 5,11 & 7 \\
\hline
\end{tabular}

Uma vez determinada a CE do pior rejeito (9,97 dS $\left.\mathrm{m}^{-1}\right)$, a partir da CE da água do canal de irrigação da área experimental $\left(0,5 \mathrm{dS} \mathrm{m}^{-1}\right)$ e da composição percentual do uso da água do canal e rejeito, quantificaram-se os valores de CE dos tratamentos seguindo a seguinte equação.

$$
C E_{\text {FINAL }}=\frac{\left(C E_{\text {REJ }} \times \%_{\text {REJ }}\right)+\left(C E_{\text {CANAL }} \times \%_{\text {CANAL }}\right)}{100} \quad \text { Eq. } 01
$$

Onde:
CEFINAL - Condutividade elétrica final da combinação das águas $\quad\left(\mathrm{dS} \mathrm{m}^{-1}\right)$
CEREs - Condutividade elétrica da água do rejeito do $\left(\mathrm{dS} \mathrm{m}^{-1}\right)$ dessalinizador
\%REJ - Percentual da água do rejeito do dessalinizador
(adimensional)
CECANAL - Condutividade elétrica da água do canal
\%canal - Percentual da água do canal
(adimensional)

A sequência de cálculo da condutividade elétrica da água de irrigação dos tratamentos de

salinidade, a partir da explanação supracitada, encontra-se na Tabela 2.

Tabela 2. Composição da água de irrigação dos tratamentos de salinidade

\begin{tabular}{|c|c|c|c|c|c|}
\hline \multirow{3}{*}{ Tratamento } & \multicolumn{4}{|c|}{ Água de irrigação } & \multirow{3}{*}{$\begin{array}{c}\text { Solução salina } \\
\text { CEEINAL }_{\text {FIN }} \\
\left(\mathrm{dS} \mathrm{m}^{-1}\right)\end{array}$} \\
\hline & \multicolumn{2}{|c|}{ Canal } & \multicolumn{2}{|c|}{ Rejeito } & \\
\hline & $\begin{array}{c}\mathrm{CE} \\
\left(\mathrm{dS} \mathrm{m}^{-1}\right)\end{array}$ & $\%$ & $\begin{array}{c}\mathrm{CE} \\
\left(\mathrm{dS} \mathrm{m}^{-1}\right)\end{array}$ & $\%$ & \\
\hline A1 & \multirow{4}{*}{0,5} & 100 & \multirow{4}{*}{9,97} & 0 & 0,5 \\
\hline A2 & & 90 & & 10 & 1,5 \\
\hline A3 & & 75 & & 25 & 3 \\
\hline A4 & & 50 & & 50 & 5 \\
\hline
\end{tabular}


O delineamento experimental foi o de blocos casualizados em esquema fatorial 5 x 4, referentes as diferentes concentrações de água salina $\left(0,5 ; 1,5 ; 3,0 ; 5,0\right.$; e $\left.7,5 \mathrm{dS} \mathrm{m}^{-1}\right)$ e 4 doses de aplicações de fertilizantes na solução nutritiva ( $\mathrm{D} 1=50 \%$ da dose recomendada; $\mathrm{D} 2$ $=100 \%$ da dose recomendada e D3 $=150 \%$ da dose recomendada na forma orgânica e D4 = $100 \%$ da dose recomendada na forma mineral aplicado por hidroponia para a cultura do pimentão), com 4 repetições, sendo utilizadas 3 plantas por unidade experimental.

O sistema de cultivo adotado no experimento foi o semi-hidropônico, sendo que cada planta foi posta em vaso plástico de 18 litros de capacidade contendo substrato inerte, composto por casca de arroz carbonizada, oriunda de indústria de beneficiamento local, e fibra de coco processada e padronizada, na proporção 1:1. No fundo dos vasos, foi colocada uma camada de cerca de $5 \mathrm{~cm}$ de brita $\mathrm{N}^{0} 1$, coberta por uma tela de polietileno para manter a separação do substrato, no intuito de favorecer a drenagem do excesso de solução.

As soluções foram aduzidas por meio de motobombas isoladas para cada salinidade. Cada motobomba aduziu solução para atender
48 vasos, representando 16 parcelas em todo o experimento, sendo 4 parcelas em cada bloco. $\mathrm{O}$ fornecimento das soluções se deu através de gotejadores autocompensantes com vazão nominal de $4 \mathrm{~L} \mathrm{~h}^{-1}$ para cada vaso.

A cultura utilizada foi o pimentão (Capsicum annuum L.) variedade All Big, cujas sementes foram semeadas em bandejas de poliestireno expandido em 128 células preenchidas com substrato comercial. As mudas foram transplantadas, com aproximadamente 30 dias após a semeadura.

O biofertilizante foi preparado por meio da fermentação anaeróbia contendo esterco fresco e água na proporção de 50\% (volume $/$ volume $=\mathrm{v} / \mathrm{v}$ ), por um período de trinta dias, em recipiente plástico hermeticamente fechado, ou seja, a mistura foi colocada deixando-se um espaço vazio de 15 a $20 \mathrm{~cm}$ na parte superior do interior das bombonas. $\mathrm{Na}$ tampa das mesmas foi adaptada uma mangueira com a outra extremidade mergulhada num recipiente com água na altura de $20 \mathrm{~cm}$, para a saída de gases (SOUSA et al., 2013).

Os teores dos nutrientes do biofertilizante se encontram na Tabela 3.

Tabela 3. Composição de macro e micronutrientes essenciais na matéria seca de biofertilizante anaeróbio

\begin{tabular}{ccccccccccc}
\hline \multicolumn{10}{c}{ Características químicas } \\
\hline $\mathrm{N}$ & $\mathrm{P}$ & $\mathrm{K}$ & $\mathrm{Ca}$ & $\mathrm{Mg}$ & $\mathrm{S}$ & $\mathrm{Na}$ & $\mathrm{Fe}$ & $\mathrm{Cu}$ & $\mathrm{Zn}$ & $\mathrm{Mn}$ \\
\hline \multicolumn{10}{c}{} & \multicolumn{10}{c}{$\left(\mathrm{g} \mathrm{L}^{-1}\right)$} & & & & & $\left(\mathrm{mg} \mathrm{L}^{-1}\right)$ & \\
\hline 1,59 & 0,32 & 0,01 & 1,58 & 0,59 & 0,01 & 92 & 425,1 & 4,28 & 15,6 & 21,8 \\
\hline
\end{tabular}

A adubação mineral foi realizada manualmente com solução nutritiva seguindo metodologia de Trani et al. (2011) para a cultura do pimentão. Já para a constituição da solução nutritiva foi seguida a recomendação proposta por Guimarães (2013), sendo N - (9,5 g planta ${ }^{-}$ $\left.{ }^{1}\right)$; P - (7,5 g planta $\left.{ }^{-1}\right)$ e $\mathrm{K}$ - (5 g planta $\left.^{-1}\right)$.

Ao final do ciclo (75 DAT) foram retiradas folhas, caule e as raízes, onde foram colocados em sacos de papel identificados de acordo com os tratamentos e levadas à estufa com circulação de ar, temperatura de $60^{\circ} \mathrm{C}$. Após $72 \mathrm{~h}$ foram determinados a massa seca.
As amostras secas em estufa foram trituradas em moinho tipo Wiley e utilizadas para determinar os teores de $\mathrm{N}$, que foram obtidas de extratos preparados por digestão sulfúrica pelo método micro-Kjeldahl, (TEDESCO et al., 1995). Os teores de Ca, Mg e $\mathrm{K}$ foram determinados através de fotometria de chama, os teores de $P$ por fotocolorimetria (MALAVOLTA, 2006).

Os resultados foram submetidos à análise de variância (ANOVA) pelo teste $\mathrm{F}$ a 1 e $5 \%$ de probabilidade e verificados quanto sua 
normalidade através do teste de Shapiro -Wilk (W). Quando verificado efeito significativo, os dados foram submetidos à análise de regressão e as médias comparadas pelo teste de Tukey com $\mathrm{P}<0,05$, utilizando-se o programa computacional Assistat.

\section{RESULTADOS E DISCUSSÃO}

Verifica-se na Tabela 4 a análise de variância para os dados de matéria seca da parte aérea (MSPA), da raiz (MSR), total (MST) e dos teores foliares de $\mathrm{N}, \mathrm{P}$ e $\mathrm{K}$ na cultura do pimentão. Observa-se que houve efeito significativo a 1\% para a interação adubação e salinidade. Analisando os efeitos isolados observa-se que para a adubação não houve efeito significativo para a variável MSPA, já a salinidade apresentou significância para todas as variáveis aos níveis de $1 \%$ e $5 \%$.

Tabela 4. Análise de variância para a massa seca da parte aérea (MSPA), da raiz (MSR), total (MST) em plantas de pimentão irrigadas com água salinas em solo com fertilizantes orgânico e mineral

\begin{tabular}{ccccc}
\hline & & \multicolumn{3}{c}{ Quadrado médio } \\
\cline { 3 - 5 } FV & GL & MSPA & MSR & MST \\
\hline Adubação (A) & 3 & $16,6102^{\text {ns }}$ & $77,7557^{* *}$ & $344,9402^{* *}$ \\
Salinidade (S) & 4 & $18,0304^{*}$ & $22,9902^{* *}$ & $167,1163^{* *}$ \\
A x S & 12 & $19,9906^{* *}$ & $26,0341^{* *}$ & $119,2474^{* *}$ \\
Bloco & 2 & $2,2150^{\text {ns }}$ & $2,0685^{\text {ns }}$ & $20,1691^{\text {ns }}$ \\
Resíduo & 38 & 6,5814 & 2,4181 & 24,5244 \\
\hline CV (\%) & & 26,56 & 28,41 & 23,65 \\
\hline
\end{tabular}

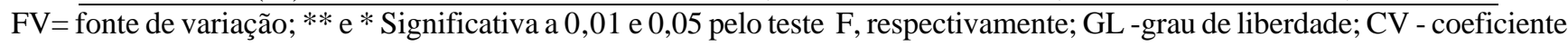
de variação

A MSPA do pimentão em função dos níveis salinos da água de irrigação ajustou-se ao modelo linear para D3 e D4, enquanto, para D1 e D2 foi o modelo polinomial quadrático, com uma MSPA máxima de 16,26 g para uma CEa de 4,28 dS m $\mathrm{d}^{-1}$ e 15,56 g para CEa de $6,21 \mathrm{dS}^{-}$ 1 , respectivamente (Figura 1). Esse resultado mostra que o biofertilizante em doses excessiva e a adubação mineral reduzem o desenvolvimento da planta sob maiores estresses salino. Tal efeito pode está associado a alta condutividade elétrica presente no insumo orgânico, provocando menor fotossíntese e consequentemente maiores fotoassimilados. Enquanto o mineral, com o decréscimo do nitrogênio afeta o desempenho diversos compostos orgânicos vitais para o vegetal. 


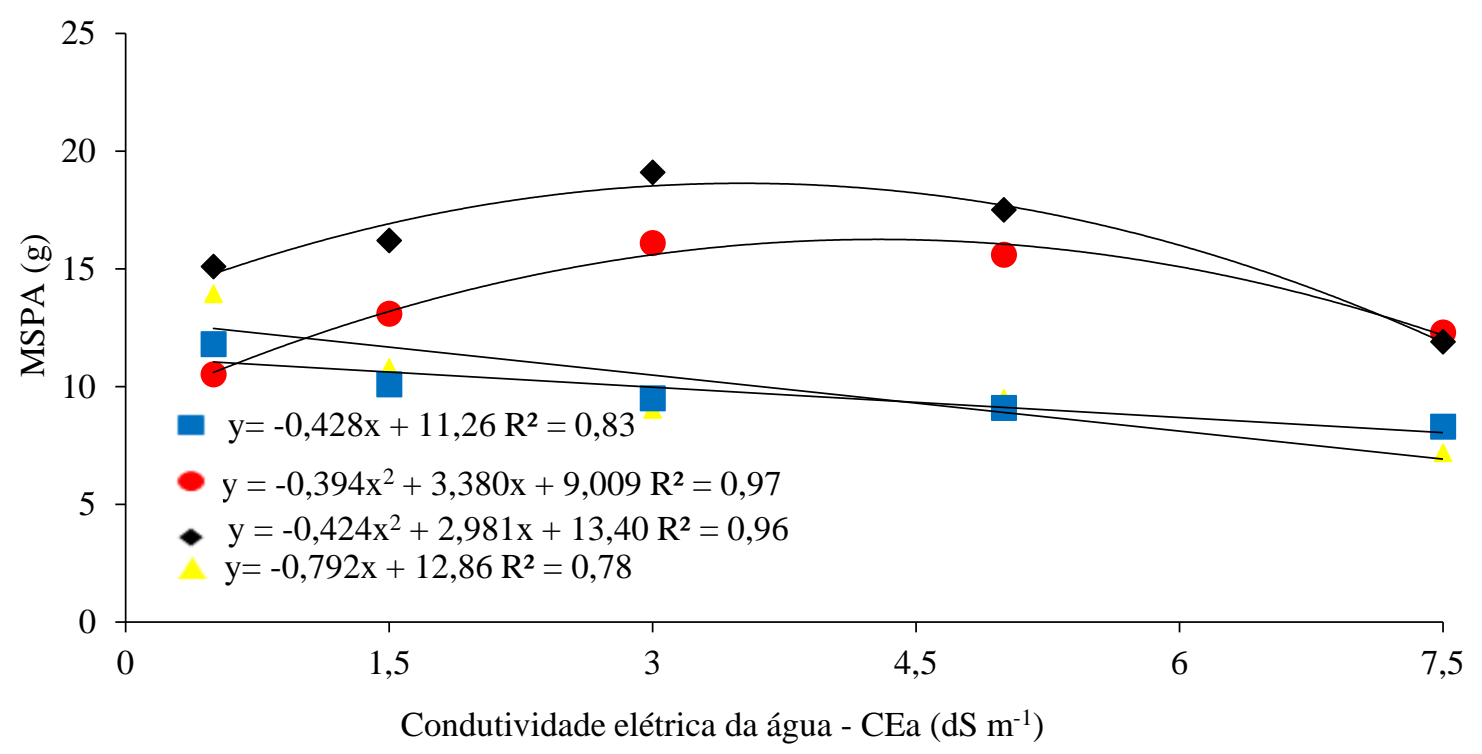

Figura 1. Massa seca da parte aérea da cultura do pimentão irrigada com águas salinas cultivadas em sistema semi-hdropônico sob doses de biofertilizante D1 - $(\bullet)$, D2 $-(\bullet)$, D3 - $(-)$ e mineral, D4 - $\left(^{\square}\right)$

Resultado similar ao desse estudo foram constatados por Lemos Neto et al. (2012), ao verificaram que os níveis crescentes de sais da água de irrigação afetaram a MSPA de plantas de pimentão cultivada em solo. Da mesma forma, Rebouças et al. (2013) constataram redução da MSPA em plantas de coentro irrigada com água de rejeito salino via hidroponia. Nascimento et al. (2011) irrigando a cultura do pimentão com água salina em solo adubado com biofertilizante bovino, também observaram redução dessa variável, porém com menor intensidade na presença desse insumo orgânico.

Semelhante a MSPA, a MSR ajustou-se ao modelo linear para a D3 e D4, enquanto, para a D1 e D2 foi o modelo polinomial quadrático, com uma MSR máxima de 6,7 g para uma CEa de 3,0 dS m${ }^{-1}$ e $6,32 \mathrm{~g}$ para uma CEa de $4,40 \mathrm{dS} \mathrm{m}^{-1}$, respectivamente (Figura 2). A inibição do sistema radicular sob condições salinas, conforme Gomes et al. (2011) é atribuída à redução da fotossíntese.

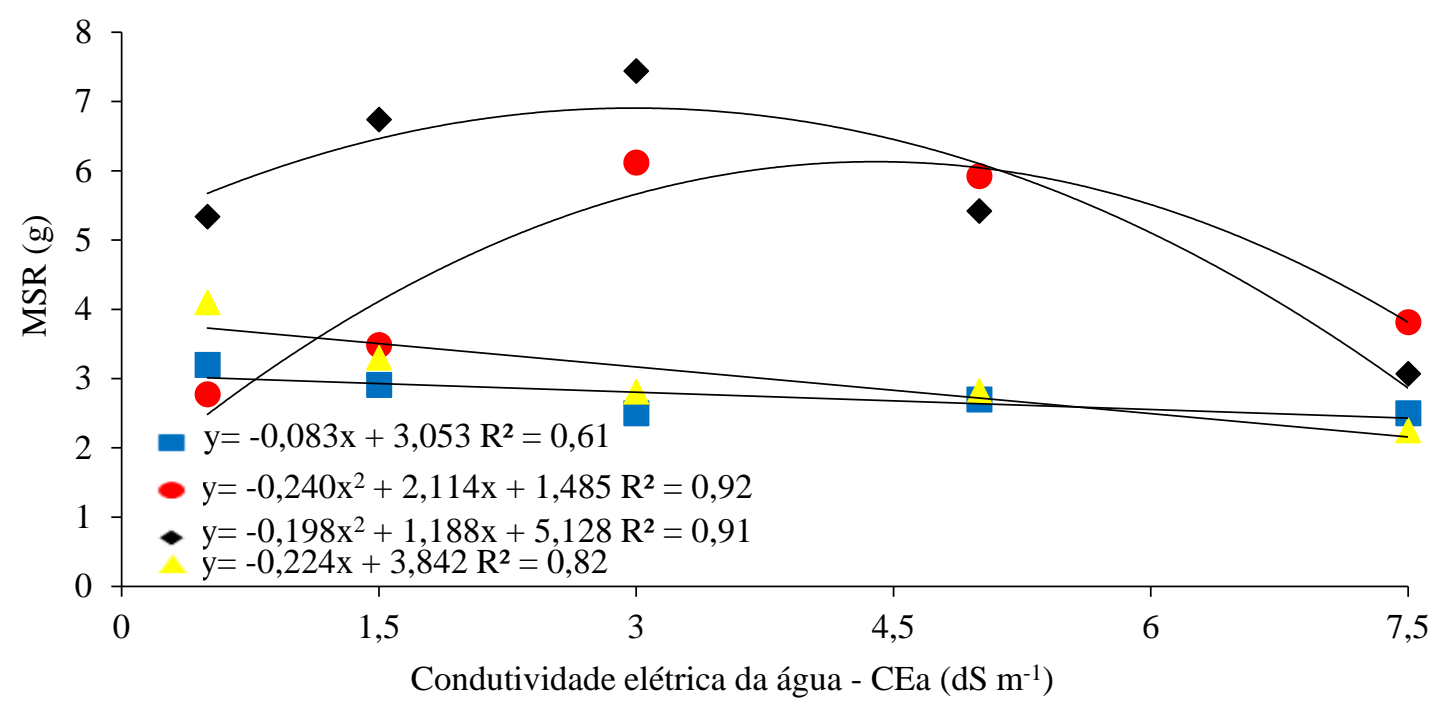

Figura 2. Massa seca da raiz da cultura do pimentão irrigada com águas salinas cultivadas em sistema semihdropônico sob doses de biofertilizante, D1 - $(\bullet)$, D2 - $(\bullet)$, D3 - $(-)$ e mineral, D4 - $(\square)$ 


\section{ESTRESSE SALINO EM PLANTAS DE PIMENTÃO EM SISTEMA SEMI-HIDROPÔNICO SOB FERTILIZAÇÃO ORGÂNICA E MINERAL}

Lemos Neto et al. (2012) também constataram, estudando os efeitos da salinidade da água de irrigação na cultura do pimentão, redução significativa da MSR. Nascimento et al. (2011) ao investigar o efeito do estresse salino em solo com e sem biofertilizante bovino, verificaram a mesma tendência desse estudo. Da mesma forma, Campos et al. (2010) irrigando plantas de girassol em solo com fertilizantes nitrogenados obtiveram declínio na MSR.

Para a MST (Figura 3) verificou-se que o modelo linear foi o que melhor se ajustou para as D3 e D4, enquanto, para a D1 e D2 foi o modelo polinomial quadrático com uma MSR máxima de 22,29 g para uma CEa de 4,26 dS m ${ }^{1}$ e de 24,15 g para uma CEa de $3,18 \mathrm{dS} \mathrm{m}^{-1}$, respectivamente.

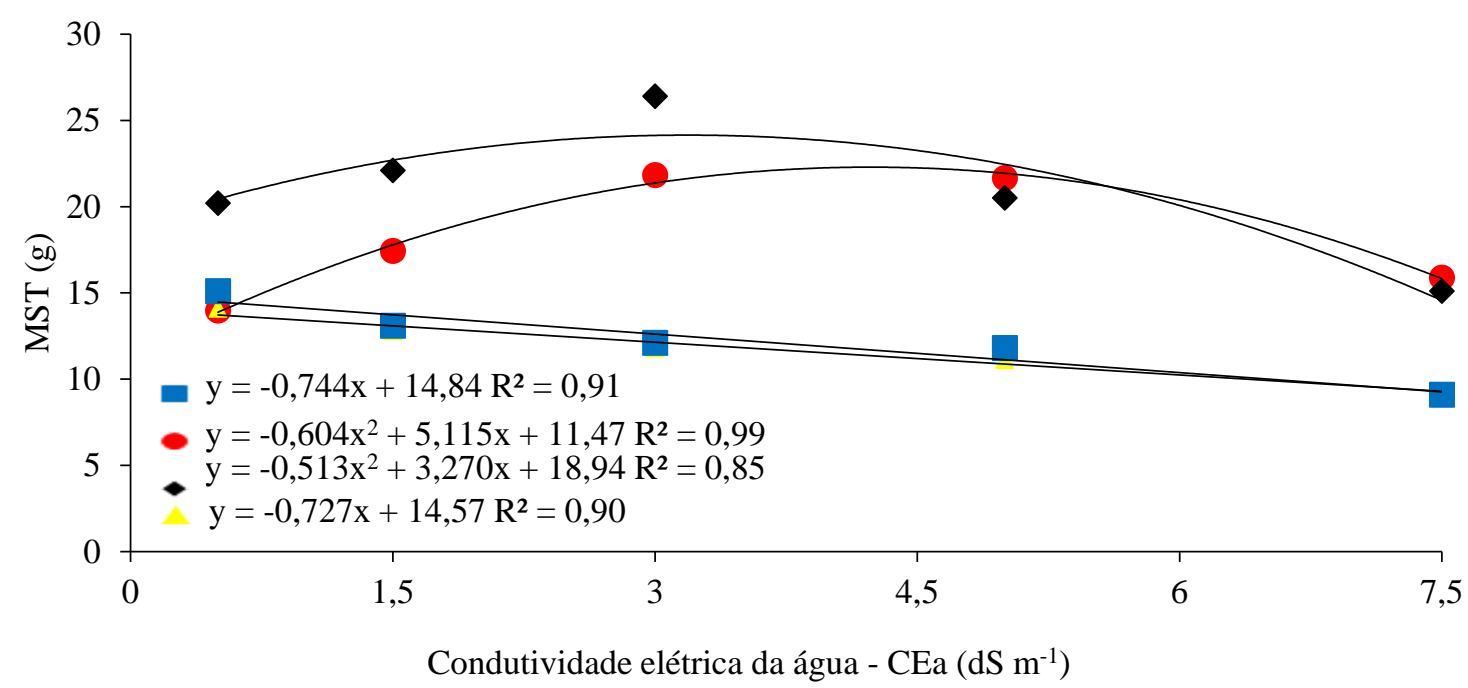

Figura 3. Massa seca total da cultura do pimentão irrigada com águas salinas cultivadas em sistema semihdropônico sob doses de biofertilizante D1 - $(\bullet)$, D2 - $(\bullet)$, D3 - $(-)$ e mineral, D4 - $(\mathbf{\square})$

Resultado similar ao desse estudo foi constatado por Nascimento et al. (2015). Esses autores concluíram que o estresse salino afetou negativamente a MST de plantas de pimentão. Similarmente, Coelho et al. (2014) ao utilizarem também obtiveram redução da MST em plantas de sorgo cultivada em ambiente salino. Campos et al. (2010) avaliando interação entre salinidade e adubação nitrogenada, constataram menor MST em plantas de girassol.

A interação entre adubação e água salinas e os efeitos isolados de cada fonte de variação, estão presentes na Tabela 5 . Excetuando o $\mathrm{Mg}$, houve efeito significativo para os teores foliares de $\mathrm{N}, \mathrm{P}, \mathrm{K}$ e Ca $(\mathrm{p}<0,01)$.

Tabela 5. Análise de variância para os teores foliares de N, P, K, Ca e Mg em plantas de pimentão irrigadas com água salinas em solo com fertilizante orgânico e mineral

Quadrado Médio

GL

Fonte de Variação

$(\mathrm{N})$

(P)

$(\mathrm{K})$

(Ca)

$(\mathrm{Mg})$

$\begin{array}{lllllll}\text { Adubação (A) } & 3 & 22,226^{* *} & 7,042^{* *} & 728,393^{* *} & 22,433^{* *} & 0,202^{\mathrm{ns}} \\ \text { Salinidade (S) } & 4 & 40,055^{* *} & 1,927^{* *} & 45,310^{* *} & 19,311^{* *} & 0,035^{\mathrm{ns}}\end{array}$


Reges et al.

$\begin{array}{ccccccc}\text { A x S } & 12 & 25,541^{* *} & 2,171^{* *} & 127,391^{* *} & 19,327^{* *} & 0,055^{\text {ns }} \\ \text { Bloco } & 2 & 3,412^{\text {ns }} & 0,038 \mathrm{~ns} & 3,787^{\text {ns }} & 0,044^{\text {ns }} & 1,684^{\text {ns }} \\ \text { Resíduo } & 38 & 2,167 & 0,0415 & 1,515 & 0,037 & 1,066\end{array}$

$\mathrm{FV}=\overline{\text { fonte de variação; }}{ }^{* *} \mathrm{e}^{*}$ Significativa a 0,01 e 0,05 pelo teste de F, respectivamente; GL -grau de liberdade; CV coeficiente de variação

O teor de nitrogênio nas folhas apresentou modelo linear crescente para as D1, D2 e D3, enquanto, a D4 o modelo polinomial quadrático foi o que melhor se ajustou com um valor máximo de 46,83g $\mathrm{kg}^{-1}$ para uma CEa de
4,51(Figura 4). Vale lembrar que os teores de N, de acordo com Villas Bôas et al. (2000), estão dentro da recomendada para a cultura (36 e $38 \mathrm{~g}$ $\left.\mathrm{kg}^{-1}\right)$. Porém, as plantas adubadas com biofertilizante evidenciaram maior aporte de $\mathrm{N}$.

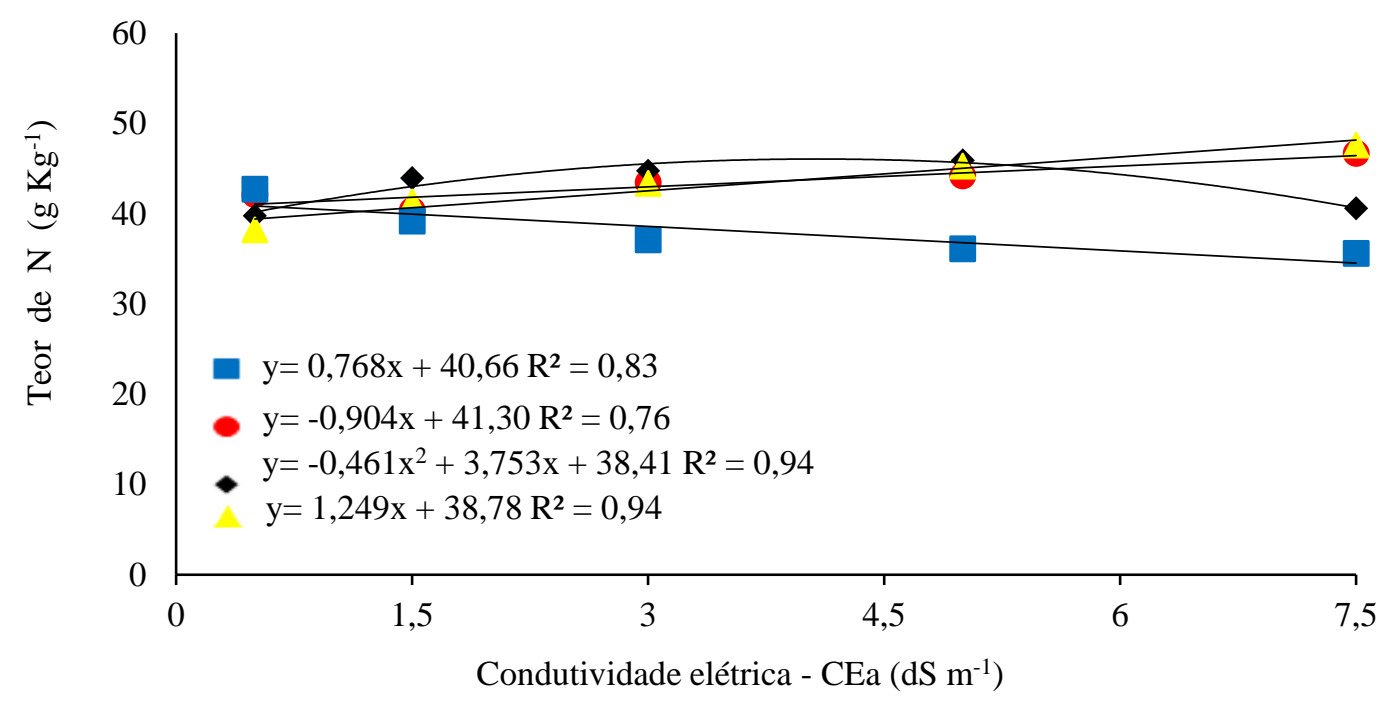

Figura 4. Teores foliares de nitrogênio em plantas de pimentão irrigada com águas salinas cultivado em sistema semi-hdropônico sob doses de biofertilizante, D1 - $(\bullet)$, D2 - ( $\bullet$ ), D3 - ( $\quad$ ) e mineral, D4 - $(\square)$

As concentrações de $\mathrm{N}$ retidas na folha foram similares às observadas por Leonardo et al. (2008) em planta de pimentão adubada com adubo orgânico sob estresse salino. Esse resultado da adubação mineral corrobora com os resultados encontrado por Silva et al. (2014), cultivando o pimentão em Argissolo irrigado com águas salinas verificaram menor o teor de $\mathrm{N}$.

É importante lembrar que o nitrogênio se destaca como um dos nutrientes mais significativos para as plantas, pois desempenha função estrutural e faz parte de diversos compostos orgânicos vitais para o vegetal como aminoácidos, proteínas e prolina, elevando a capacidade de ajustamento osmótico das plantas à salinidade (LIMA et al., 2016).

O aumento da salinidade da água de irrigação inibiu linearmente os teores de $\mathrm{P}$ nos tratamentos adubados com 0 biofertilizante (D1, D2 e D3). Já para adubação mineral, o modelo polinomial quadrático foi o melhor que se ajustou com teor foliar de $\mathrm{P}$ máximo de 5,21 $\mathrm{g} \mathrm{kg}^{-1}$ para uma CEa de 3,76 (Figura 5). Excetuando a adubação mineral, os demais valores estão abaixo do recomendado por Vilas Bôas et al.(2000), que fica entre 4 a $8\left(\mathrm{~g} \mathrm{~kg}^{-1}\right)$. 


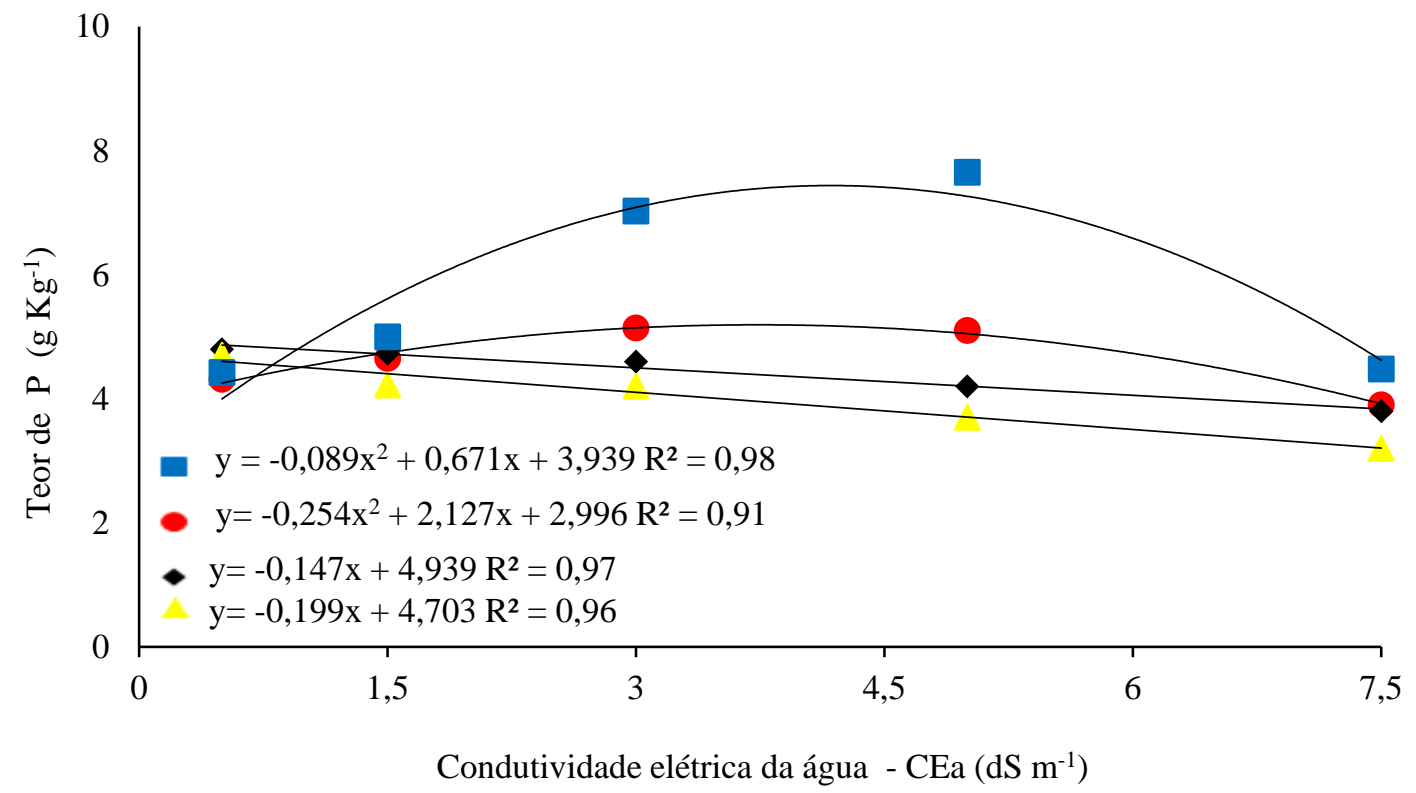

Figura 5. Teores foliares de fósforo em plantas de pimentão irrigada com água salina cultivado em sistema semihidropônico sob doses de biofertilizante, D1 - $(\bullet)$, D2 - ( $\bullet$ ), D3 - ( $)$ e mineral, D4 - $(\square)$

Esses resultados estão de acordo com os de Leonardo et al. (2008), ao avaliarem os teores foliares de $\mathrm{P}$ em planta de pimentão sob adubação orgânica e irrigada com águas salinas. Silva et al. (2014) irrigando plantas de pimentão em solo com adubação mineral, também verificaram aumento do teor de $\mathrm{P}$ em folhas de pimentão com o incremento da salinidade.
O aumento dos níveis salinos da água de irrigação estimulou linearmente os teores de K, com superioridade para a adubação mineral aplicada via hidroponia (Figura 6), sendo que os teores de $K$ estão acima da faixa adequada para o pimentão $(30,0$ - 50,0 $\mathrm{g} \mathrm{kg}^{-1}$ ) conforme (VILAS BÔAS et al., 2000).

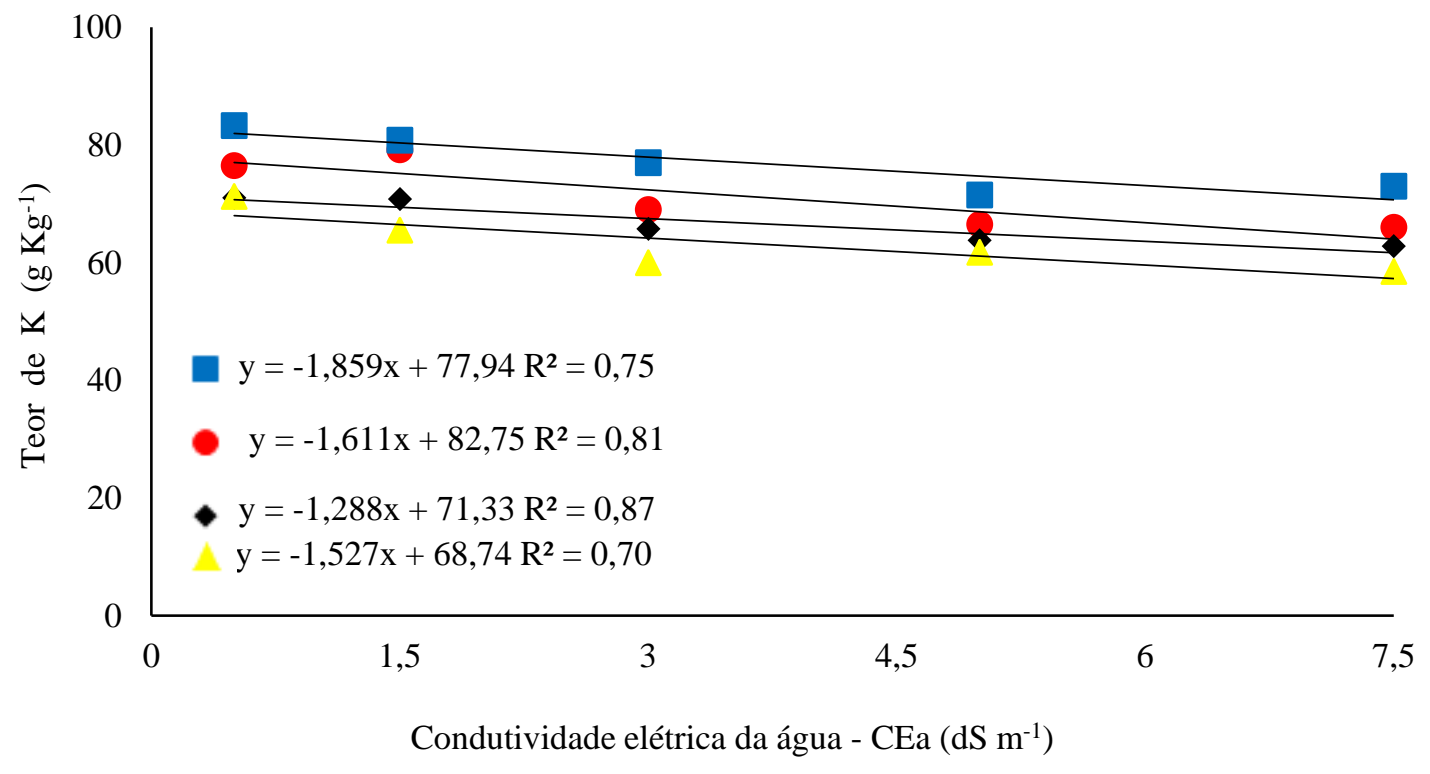

Figura 6. Teores foliares de potássio em plantas de pimentão irrigada com águas salinas cultivadoem sistema semi-hidropônicosob doses de biofertilizante, D1 - $\left(^{\bullet}\right)$, D2 - $(\bullet)$, D3 - ( ${ }^{-}$) e mineral, D4 - $\left(^{\square}\right)$ 
Resultados relacionados aos teores de $\mathrm{K}$ nas folhas foram semelhantes aos encontrados por Leonardo et al. (2008), cultivando plantas de pimentão em solo com adubo orgânico irrigada com água salinas. Sousa et al. (2010) relatam que o aumento da concentração de sódio no meio radicular pode inibir a absorção de potássio devido a relação competitiva entre esses cátions monovalentes.
Pelos resultados, verifica-se que o estresse salino afetou os teores de cálcio, apresentando o modelo linear decrescente para as D1, D2 e D4 e polinomial quadrático para a $\mathrm{D} 3$, com valores máximos de teores de Ca de 22,25 $\mathrm{g} \mathrm{kg}^{-1}$ para uma CEa de 4,1 dS m$~^{-1}$. Lucena et al. (2012) verificaram reduções nos teores de Ca nas folhas de manga em função da aplicação de níveis crescentes de $\mathrm{NaCl}$.

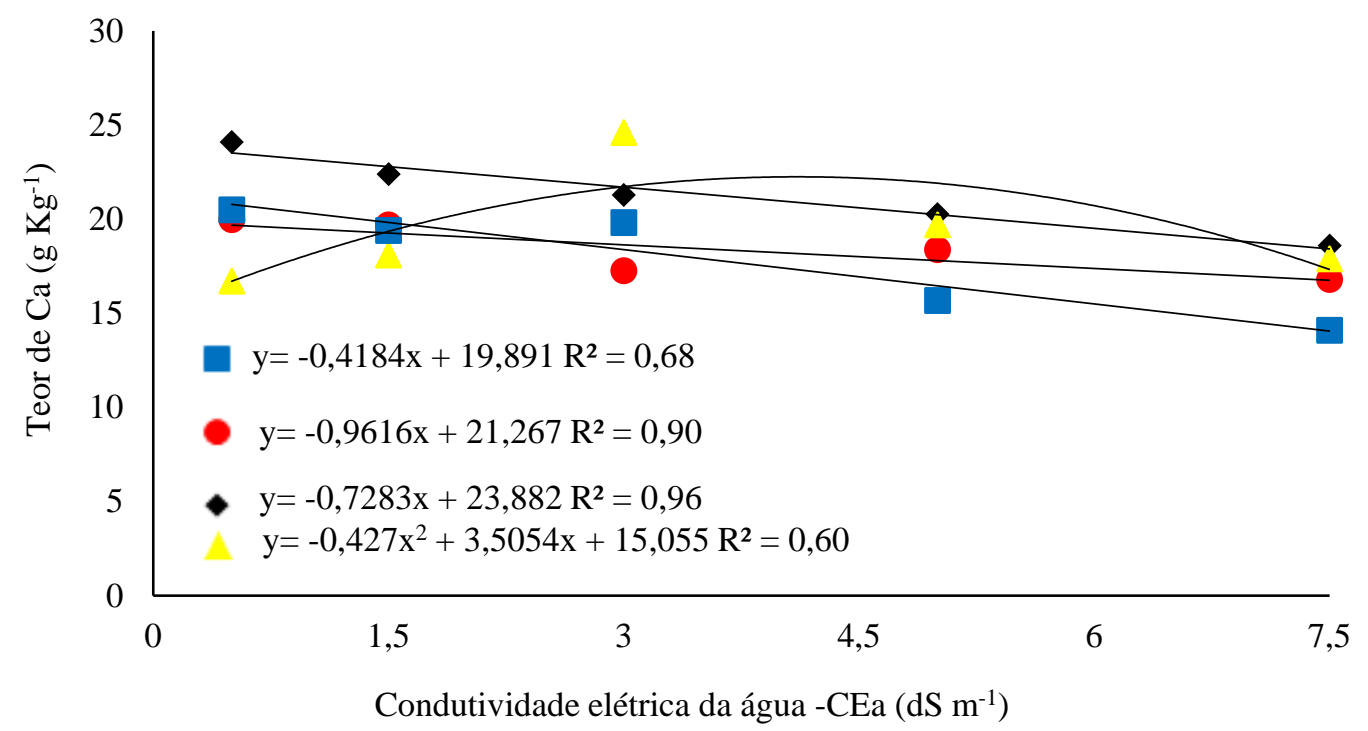

Figura 7. Teores foliares de cálcio em plantas de pimentão irrigada com águas salinas cultivado em sistema semihidropônico sob doses de biofertilizante, D1 - $(\bullet)$, D2 - ( $\bullet$ ), D3 - $(-)$ e mineral, D4 - $\left({ }^{*}\right)$

Ressalta-se que o íon Ca é um elemento essencial para a integridade da membrana plasmática das células vegetais, e sua deficiência pode afetar a absorção de íons, principalmente o K (LIMA et al., 2016).

Silva et al. (2014) trabalhando com a cultura do pimentão em casa de vegetação, também evidenciaram efeito negativo dos teores de Ca em plantas de pimentão sob estresse salino. Por outro lado, Sousa et al. (2010) verificaram aumento da concentração de Ca em folhas de plantas de milho irrigadas com água salinas.

Silva et al. (2011) avaliando os teores foliares de $\mathrm{Ca}$ em plantas de feijão-de-corda irrigadas com águas salinas em solo com biofertilizante bovino, constataram efeito oposto ao desse estudo. Esses autores relatam que o insumo orgânico atenuou o efeito do estresse salino da água de irrigação.

\section{CONCLUSÕES}

A irrigação com água salina até $3,0 \mathrm{dS} \mathrm{m}^{-1}$ promove maior massa seca da parte aérea, raiz e total da cultura do pimentão quando adubada com $100 \%$ da dose recomendada de biofertilizante.

A salinidade da água de irrigação afeta o teor de $\mathrm{N}$ com $100 \%$ da dose recomendada de biofertilizante e na adubação mineral, o teor de P com 50, 100 e 150\% da dose recomendada de biofertilizante e a partir da CEa 3,76 com adubação mineral e o teor de Ca e K em todas as adubações.

O cultivo do pimentão adubado com fonte orgânica ou mineral em sistema semihidropônico é uma alternativa viável para a utilização da água de rejeito da dessalinização evitando a contaminação do lençol freático. 


\section{REFERÊNCIAS}

AYERS, R. S.; WESTCOT, D. W.A qualidade da água na agricultura. Campina Grande:1999. 153p.

CAMPOS, M. S.; OLIVEIRA, F. A.; OLIEVEIRA, F. R. A.; SILVA, R. C. P.; CÂNDIDO, W. S. Efeito da salinidade e fontes de nitrogênio na matéria seca do girassol. Revista Verde, v.5, n. 3, p.65 -171, 2010.

CAMPOS. M. S. VIEIRA, M. S.; SANTOS, A. F.; OLIVEIRA, W. M.; NASCIMENTO, J. A. M.Água salina e esterco bovino líquido na formação de mudas de goiabeira cultivar paluma. Revista Brasileira de Fruticultura,v. 32, n.1, p. 251-261, 2010.

CAVALCANTE, L. F.; REBEQUI, A. M.; SENA, G. S. A.; NUNES, J. C. Irrigação com águas salinas e uso de biofertilizante bovino na formação de mudas de pinhão-manso. Irriga, Botucatu, v. 16, n. 3, p. 288-300, 2011.

COELHO, D.S.; SIMÕES. W. L, MENDES, A. M. S.; DANTAS, B. F.; RODRIGUES, J. A. S., SOUZA, M. A.Germinação e crescimento inicial de variedades de sorgo forrageiro submetidas ao estresse salino. Revista Brasileira de Engenharia Agrícola e Ambiental, v.18, n.1, p. 25-30, 2014.

\begin{tabular}{lccc} 
FOOD & AND & \multicolumn{2}{c}{ AGRICULTURE } \\
ORGANIZATION. & (FAO), & WORLD \\
HEALTH & ORGANIZATION. & (WHO).
\end{tabular}
Food Safety Risk Analysis. An Overview and Framework Manual. PART I. Provisional Edition. Rome: 2013. Disponível em:

http://www.fsc.go.jp/sonota/foodsafety_riskana lysis.pdf. Acesso em: 12 ago. 2017.

GUIMARÃES, J.W.A. 2013. Produção orgânica irrigada e rentabilidade do pimentão amarelo sob diferentes ambientes e dosagens de biofertilizante. Fortaleza. 2013,136f. (Tese de Doutorado) - Universidade Federal do Ceará, Fortaleza, Brasil.
GOMES, K. R.; AMORIM, A. V.; FERREIRA, F. J.; FILHO, F. L.; LACERDA, C. F.; GOMESFILHO, E. Respostas de crescimento e fisiologia do milho submetido a estresse salino com diferentes espaçamentos de cultivo. Revista Brasileira de Engenharia Agrícola e Ambiental, v.15, n.4, p.365-370, 2011.

GOMES, K. R.; SOUSA, G. G.; LIMA, F. A.; VIANA, T. V. A.; AZEVEDO, B. M.; SILVA, G. L. Irrigação com água salina na cultura do girassol (Helianthus Annuus L.) Em solo com biofertilizante bovino. Revista Irriga, v.20, n.4, p.680-693, 2015.

HORTIBRASIL. Norma de classificação do pimentão para o programa brasileiro para a melhoria dos padrões comerciais e embalagens de hortigranjeiros. Disponível em: http://http://www.hortibrasil.org.br/classificaca o/pimentao/pimentao.html . Último acesso em 02 agosto 2017.

LEMOS NETO, H. S.; NOGUEIRA, S. O.; ALENCAR, T. S.; LIMA, M. V. S.; SANTOS, W. O.Análise do crescimento inicial do pimentão submetido a diferentes níveis de salinidade. Enciclopédia Biosfera, v. 8, n. 14, p.42-50, 2012.

LEONARDO, M.; BROETTO, F.; VILLAS BOAS, R. L.; MARCHESE, J. A.; FÁBIO BECHELLI TONIN, F. B.REGINA, M. Estado nutricional e componentes da produção de plantas de pimentão conduzidas em sistema de fertirrigação durante indução de estresse salino em cultivo protegido. Bragantia, v.67, n. 4, p. 883-889, 2008.

LIMA, G. S. L.; OLIVEIRA, G. S.; GHEYI, H. R.; SOARES, L. A. A.; LACERDA, C. F.; SANTOS, J. B.; ARAÚJO, B. M. Cultivationofcoloredcottonirrigatedwith saline waterunderpotassiumandnitrate/ammoniumferti lization. AfricanJournalofAgricultural, v.11, p.32-39, 2016.

LUCENA, C. C.; SIQUEIRA' D. L.; MARTINEZ'H. E. P.; CECON, P. R. Efeito do estresse salino na absorção de nutrientes em 
mangueira.Revista Brasileira de Fruticultura, v.34, n. p. 297-308, 2012.

MALAVOLTA, E.Manual de nutrição mineral de plantas. São Paulo, Brasil, 2006, 631p. Munns R (2005) Genes and salt tolerance: bringing them together.

New Phytologist, 167:645-663.

NASCIMENTO, I. B.; MEDEIROS, J. F.; ALVES, S. S. V.; LIMA, B. L. C.; SILVA, J. L. A. Desenvolvimento inicial da cultura do pimentão influenciado pela salinidade da água de irrigação em dois tipos de solos. AgropecuáriaCientífica no Semiárido, v.11, n.2, p. 37-43, 2015.

NASCIMENTO, J. A. M.; CAVALCANTE, L. F.; SANTOS, P. D.; SILVA, S. A.; VIEIRA, M. V.; OLIVEIRA, A. P. Efeito da utilização de biofertilizante bovino na produção de mudas de pimentão irrigadas com água salina.Revista Brasileira de Ciências Agrárias, v.6, n. 2, p. 258-264, 2011.

REBOUÇAS, J.R. L. FERREIRA NETO, M.; DIAS, N. S.; SOUZA NETO, O. N.; DINIZ, A. A.; LIRA, R. B. Cultivo hidropônico de coentro com uso de rejeito salino.Irriga, v.18, n.4,p. 624-634, 2013.

SANTOS JÚNIOR, J. A.; GHEYI, H. R.; DIAS, N. S.;GUEDES FILHO, D. H. Crescimento do girassol em sistema semi-hidropônicosob estresse salino e densidades de plantio. Irriga,v.20, n. 2,233-247, 2015.

SILVA, A. O. FRANÇA E SILVA, E. F.; SANTOS, A. N.; KLAR, A. E. Consumo hídrico da rúcula em cultivo hidropônico nft utilizando rejeitos de dessalinizador em IbimirimPE.Irriga, v.17, n.1, 114-125, 2012.
SILVA, F.L. B.; LACERDA, C. F.;SOUSA, G. G.; NEVES, A. L. R.; SILVA, G. L.; SOUSA, C. H. C. Interação entre salinidade e biofertilizante bovino na cultura do feijão-decorda. Revista Brasileira de Engenharia Agrícola e Ambiental, v.15, n.4, p. 383-389, 2011.

SILVA, J.L. A. SILVA, J. L. A.; ALVES, S. S. V.; NASCIMENTO, L. B.; MEDEIROS, J. F.; TARGINO, A. J. O.; LINHARES, P.Teores foliares no pimentão submetido à estresse salino em diferentes solos. Agropecuária Científica no Semiárido, v.10, n. 3, p.77-82, 2014.

SOUSA, G. G. SOUSA, G. G.; LACERDA, C. F.; CAVALCANTE, L. F.; GUIMARÃES, F. V. A.; BEZERRA, M. E. J.; SILVA, G. L. Nutrição mineral e extração de nutrientes de planta de milho irrigada com água salina. Revista Brasileira de Engenharia Agrícola e Ambiental, v.14, n.11, p.1143-1151, 2010.

SOUSA, G. G.; VIANA, T. V. A.; BRAGA, E. S.; AZEVEDO, B. M.; MARINHO, A. B.; BORGES, F. R. M. Fertirrigação com biofertilizante bovino: Efeitos no crescimento, trocas gasosas e na produtividade do pinhãomanso. Revista Brasileira de Ciências Agrárias, Recife,v.8, n. 3, p. 503-509, 2013.

TEDESCO, M. J. et al.Análise de solo, plantas e outros materiais. Porto Alegre, Brasil, 1995, 174p.

TRANI, P. E.; TRANI, A.L. Fertilizantes: Cálculo de Fórmulas Comerciais. Campinas, Brasil, 2011, 29 p.

VILLAS BOAS, R.L.; KANO, C.; LIMA, C. P.; NANETTI, F. A.; FERNANDES. D. M. Efeito de doses de nitrogênio aplicado de forma convencional e através da fertirrigação na cultura do pimentão. Horticultura Brasileira,v.18, suplemento,p.801-802, 2000. 